\title{
Predictors of coronary intervention-related myocardial infarction in stable angina patients pre-treated with statins
}

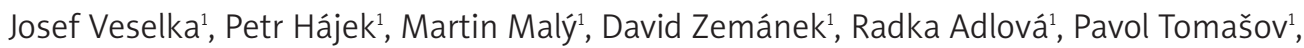
Lucie Martinkovičová', David Tesařr, Pavel Červinka²

1Department of Cardiology, $2^{\text {nd }}$ Medical School, Charles University, University Hospital Motol, Prague, Czech Republic

2Department of Cardiology, Masaryk Hospital, Ústí nad Labem, Czech Republic

Submitted: 29 July 2010

Accepted: 24 August 2010

Arch Med Sci 2011; 7, 1: 67-72

DOI: 10.5114/aoms.2011.20606

Copyright @ 2011 Termedia \& Banach

\section{Abstract}

Introduction: Peri-procedural myocardial infarction (PMI) is a frequent and prognostically important complication of percutaneous coronary intervention $(\mathrm{PCl})$. This study was designed to determine the predictors of $\mathrm{PMI}$ in patients pre-treated with statins.

Material and methods: A total of 418 stable angina pectoris patients taking statins and aspirin were included. All the patients underwent $\mathrm{PCl}$. Serum concentrations of creatine kinase (CK-MB mass) and troponin I (TnI) were measured prior to and then within 16 to 24 hours after PCI. The incidence of PMI was assessed using the established criteria ( $\geq 3$ times upper limit of normal). Results: Four hundred and eighteen stable patients ( $63 \pm 10$ years, $68 \%$ males) were treated by $\mathrm{PCl}$. The technical success rate of $\mathrm{PCl}$ was $99 \%$. The incidence of PMI based on CK-MB mass or Tnl release was $12 \%$ (PMI group). There were no significant differences in baseline clinical and procedural characteristics between PMI and non-PMI groups except for the balloon inflation time $(40 \pm 44 \mathrm{~s}$ vs. $26 \pm 27 \mathrm{~s} ; p=0.02)$ and the proportion of treated type $\mathrm{C}$ lesions (42\% vs. $28 \% ; p=0.03)$. In multivariate analysis, the independent predictors of PMI were balloon inflation time $(\mathrm{OR}=1.01 ; 95 \% \mathrm{Cl} 1.001-1.020 ; p=0.02)$ and preprocedural level of $\mathrm{C}$-reactive protein $(\mathrm{OR}=1.38 ; 95 \% \mathrm{Cl} 1.059-1.808 ; p=0.02)$. Conclusions: These results suggest that $\mathrm{C}$-reactive protein and balloon ischaemic time are independent predictors of PMI in stable angina patients pre-treated with statins.

Key words: C-reactive protein, stent, myocardial infarction.

\section{Introduction}

Post-interventional cardiac marker release is considered to represent peri-procedural myocardial infarction (PMI), which is a relatively common complication of percutaneous coronary intervention $(\mathrm{PCl})$, mostly with a silent clinical course [1]. Recently, a relationship has been reported between PMI and long-term mortality [2, 3]. Therefore, the prevention of $\mathrm{PMI}$ will improve the long-term $\mathrm{PCl}$ outcome.

There is a growing body of evidence supporting beneficial cholesterolindependent effects ("pleiotropic" effects) of statins that are largely accounted for by a favourable action profile of statins on endothelial

\author{
Corresponding author: \\ Josef Veselka MD \\ Department of Cardiology \\ $2^{\text {nd }}$ Medical School \\ Charles University \\ University Hospital Motol \\ V uvalu 84 \\ Prague 5, 15000 \\ Czech Republic \\ E-mail: \\ veselka.josef@seznam.cz
}


function, bioavailability of nitric oxide, inflammation, thrombosis, apoptosis, platelet activation, plaque stability, arrhythmias, and angiogenesis [4, 5]. Additionally, Ridker et al. have recently demonstrated reduction of cardiovascular events in apparently healthy persons without hyperlipidaemia but with elevated C-reactive protein (CRP) treated by rosuvastatin [6]. Although the studies investigating the effect of statin pre-treatment on the incidence of PMI are inconclusive [7-10], on the basis of existing literature it seems to be recommendable to start treating with statins all patients with coronary artery disease immediately, irrespective of possible coronary intervention.

Since the crucial point of PMI management is prevention, a lot of approaches including the determination of PMI predictors have been studied up to now [11-13]. This retrospective study was designed to determine the predictors of PMI in stable patients pre-treated with statins undergoing elective $\mathrm{PCl}$.

\section{Material and methods}

Prospectively collected data on 418 patients with stable angina pectoris or evidence of inducible myocardial ischaemia in a cardiac stress test, who were referred for percutaneous coronary intervention (PCI) of a de-novo lesion $50-90 \%$ of luminal diameter, were retrospectively analysed in this study. Patients suffering from acute coronary syndromes in the preceding three weeks were excluded. All the patients had to be pre-treated with statins and aspirin for $\geq 2$ days. Statins used prior to $\mathrm{PCl}$ are summarized in Table I. All study protocols were approved by the local ethics committee, and all the patients provided written informed consent.

Table I. Statins used prior to percutaneous coronary intervention

\begin{tabular}{|lccc|}
\hline Type of statin & $\begin{array}{c}\text { PMI } \\
(n=52)\end{array}$ & $\begin{array}{c}\text { Non-PMI } \\
(n=366)\end{array}$ & $P$ value \\
\hline Atorvastatin $10 \mathrm{mg} /$ day [\%] & 6 & 6 & $\mathrm{NS}$ \\
\hline Atorvastatin $20 \mathrm{mg} /$ day [\%] & 21 & 15 & $\mathrm{NS}$ \\
\hline Atorvastatin $40 \mathrm{mg} /$ day [\%] & 6 & 3 & $\mathrm{NS}$ \\
\hline Atorvastatin $80 \mathrm{mg} /$ day [\%] & 0 & 0 & $\mathrm{NS}$ \\
\hline Fluvastatin $20 \mathrm{mg} /$ day [\%] & 0 & 2 & $\mathrm{NS}$ \\
\hline Fluvastatin $40 \mathrm{mg} /$ day [\%] & 2 & 0 & $\mathrm{NS}$ \\
\hline Fluvastatin $80 \mathrm{mg} /$ day [\%] & 2 & 6 & $\mathrm{NS}$ \\
\hline Simvastatin $10 \mathrm{mg} /$ day [\%] & 4 & 4 & $\mathrm{NS}$ \\
\hline Simvastatin $20 \mathrm{mg} /$ day [\%] & 44 & 58 & $\mathrm{NS}$ \\
\hline Simvastatin $40 \mathrm{mg} /$ day [\%] & 15 & 5 & 0.004 \\
\hline Lovastatin $20 \mathrm{mg} /$ day [\%] & 0 & 1 & $\mathrm{NS}$ \\
\hline
\end{tabular}

$P M I-$ procedural myocardial infarction
Stenoses that reduced the lumen diameter by $50 \%$ (visual estimation) or more were considered significant. Quantitative coronary analysis was used only when the assessment of two cardiologists was disparate, with regard to categorization of lesion severity $\geq 50 \%$. The coronary artery tree was divided into three compartments (left anterior descending artery, left circumflex artery, and right coronary artery) for categorization of one, two, and three vessel coronary artery disease. Coronary lesions were classified as either type A (discrete, concentric), B1 (tubular, eccentric), B2 (irregular contour, moderately angulated, calcified, bifurcation requiring double wiring), or C (diffusely diseased artery, long lesion, extremely angulated, inability to protect significant side branch).

A weight-adjusted bolus of heparin was given routinely at the beginning of the procedure (70-100 IU/kg), to keep the clotting time within 250-300 s. Intracoronary isosorbide dinitrate was administered (0.2-0.5 mg) just prior to $\mathrm{PCl}$. Clopidogrel was given either in a loading dose (300-600 mg) one day before (in $96 \%$ of patients) or immediately after the $\mathrm{PCl}$. Glycoprotein IIb/IIla inhibitors were not used in this study. Numbers of treated lesions and inflations were determined by the operators as clinically indicated. Stent delivery was routinely followed by high-pressure balloon inflations (> $15 \mathrm{~atm}$ ). In selected cases, direct coronary stenting was used. Balloon ischaemic time included the whole time in which the treated artery was occluded by an inflated balloon catheter (balloon dilation or stent implantation). Technical success was defined as residual diameter stenosis $<20 \%$ by visual estimation and the ultimate achievement of thrombolysis in myocardial infarction (TIMI) flow grade 3 .

The primary end-point of this study was the occurrence of PMI as determined by the postinterventional release of troponin I (TnI), and/or creatine kinase-MB (CK-MB) mass $\geq 3$ times upper limit of normal. Blood samples were taken prior to the $\mathrm{PCl}$ and then within 16-24 h thereafter. In patients experiencing myocardial infarction within $24 \mathrm{~h}$ following the $\mathrm{PCl}$, further measurements were taken $48 \mathrm{~h}$ after the $\mathrm{PCl}$. The patients were divided into two groups (PMI group and non-PMI group) according to the presence of PMI, and these groups were compared.

Continuous variables are expressed as mean \pm SD, discrete variables as counts and/or percentages. Differences between group characteristics were compared using the $\chi^{2}$ test (Fisher's exact test) for categorical variables and Student's test for continuous variables. The Mann-Whitney $U$ test was used to analyse the difference between the medians in both groups of patients. The degree of association between the post-procedural Tnl and 
CRP level (balloon inflation time) was calculated by Spearman rank correlation. Multivariate analyses were performed using a logistic regression to identify predictors of PMI based on postinterventional release of Tnl and/or CK-MB mass. The variables included in the logistic regression analysis are as follows: age, gender, diabetes, hypertension, history of MI, total cholesterol level, HDL-cholesterol level, LDL-cholesterol level, triglyceride level, C-reactive protein (hs-CRP) level, clopidogrel pre-treatment, treatment of type $C$ lesion, balloon ischaemic time. Since the raw hs-CRP data were asymmetrical, the logarithmic transformation (log CRP) was used to obtain a normal distribution. The results of multivariate analysis were described as odds ratios (OR) with $95 \%$ confidence interval $(95 \% \mathrm{Cl})$. A $p$-value of $<0.05$ was considered statistically significant.

\section{Results}

A total of 418 patients with stable angina pectoris were eligible and underwent $\mathrm{PCl}$. No patient died during the hospital stay. Fifty-two (12\%) patients suffered from PMI based on Tnl (48 pts.) and/or CKMB mass (21 pts.) release. These patients constituted the PMI group. The incidence of PMI, based on biomarkers release, are summarized in Table II.

The baseline clinical variables were comparable between the PMI and non-PMI group (Table III). Angiographic and procedural characteristics were similar in both groups, except for higher occurrence of treated type C lesions ( $42 \%$ vs. $28 \% ; p=0.03$ ) and longer balloon inflation time $(40 \pm 44 \mathrm{~s}$ vs. $26 \pm 27 \mathrm{~s} ; p=0.02$ ) (Table IV).

Multivariate analysis was performed to identify the predictors of PMI, as was pre-specified. In this model, only balloon inflation time $(\mathrm{OR}=1.01 ; 95 \%$ $\mathrm{Cl} 1.001-1.020 ; p=0.02)$ and pre-procedural level of $\log \mathrm{CRP}(\mathrm{OR}=1.38 ; 95 \% \mathrm{Cl} 1.059-1.808 ; p=0.02)$ were identified as independent predictors of PMI (Table V). There was a weak correlation between hs-CRP and post-procedural Tnl levels ( $r=0.15$; 95\% $\mathrm{Cl} 0.05-0.27 ; p=0.017$ ) (Figure 1). Similarly, there was a statistically significant correlation between Tnl level and balloon ischaemic time ( $r=0.32 ; 95 \%$ Cl 0.09-0.52; $p=0.007$ ) (Figure 2).

\section{Discussion}

To the best of our knowledge, this is the first study to date evaluating predictors of $\mathrm{PMI}$ in stable angina pectoris patients taking aspirin and statins. The results of this study suggest that CRP and balloon inflation time are independent preprocedural and procedural predictors of PMI, respectively.

Previously, pre-procedural risk predictors for $\mathrm{PMI}$, such as age, acute coronary syndromes,
HDL-cholesterol level, and inflammatory markers, have been reported $[11,13,14]$. Similarly, procedural risk factors for PMI, such as multivessel disease, complex lesions and interventional complications (coronary dissection, embolization or occlusion) have been determined [11]. On the other hand, it was hypothesized that pre-procedural statin treatment decreases the extent of PMI as a function of myocardial inflammatory cell accumulation

Table II. Incidence of peri-procedural myocardial infarction based on $\mathrm{Tnl}$ and CK-MB mass release

\begin{tabular}{|c|c|c|c|}
\hline Type of statin & $\begin{array}{c}\text { PMI } \\
(n=52)\end{array}$ & $\begin{array}{l}\text { Non-PMI } \\
(n=366)\end{array}$ & $P$ value \\
\hline \multicolumn{4}{|l|}{ Baseline } \\
\hline \multicolumn{4}{|l|}{ Troponin I [ng/ml] } \\
\hline Median & 0.1 & 0.1 & NS \\
\hline Interquartile range & $0.1-0.1$ & $0.1-0.1$ & \\
\hline \multicolumn{4}{|l|}{ CK-MB mass $[\mathrm{ng} / \mathrm{ml}]$} \\
\hline Median & 1.6 & 1.1 & NS \\
\hline Interquartile range & $0.868-2.045$ & $0.735-1.67$ & \\
\hline \multicolumn{4}{|l|}{ Post-PCl } \\
\hline \multicolumn{4}{|l|}{ Troponin I [ng/ml] } \\
\hline Median & 2.611 & 0.5 & $<0.01$ \\
\hline Interquartile range & $1.7-5.368$ & $0.1-0.5$ & \\
\hline \multicolumn{4}{|l|}{ CK-MB mass [ng/ml] } \\
\hline Median & 6.22 & 1.22 & $<0.01$ \\
\hline Interquartile range & $4.65-11.11$ & $0.7-1.83$ & \\
\hline
\end{tabular}

$P M I$ - procedural myocardial infarction

Table III. Baseline clinical characteristics of PMI and non-PMI group

\begin{tabular}{|lccc|}
\hline Type of statin & $\begin{array}{c}\text { PMI } \\
(n=52)\end{array}$ & $\begin{array}{c}\text { Non-PMI } \\
(n=366)\end{array}$ & $P$ value \\
\hline Sex (male) [\%] & 71 & 68 & NS \\
\hline Angina pectoris class (CCS) & $1.5 \pm 1.4$ & $1.8 \pm 1.2$ & NS \\
\hline $\begin{array}{l}\text { History of myocardial } \\
\text { infarction [\%] }\end{array}$ & 60 & 54 & NS \\
\hline Smokers [\%] & 27 & 30 & NS \\
\hline Hypertension [\%] & 77 & 75 & NS \\
\hline $\begin{array}{l}\text { Total plasma cholesterol } \\
\text { [mmol/l] }\end{array}$ & $4.2 \pm 1.1$ & $4.6 \pm 2.2$ & NS \\
\hline LDL cholesterol [mmol/I] & $3 \pm 0.8$ & $2.7 \pm 0.9$ & NS \\
\hline HDL cholesterol [mmol/l] & $1.1 \pm 0.4$ & $1.1 \pm 0.4$ & NS \\
\hline $\begin{array}{l}\text { Plasma triglyceride } \\
\text { [mmol/l] }\end{array}$ & $1.6 \pm 1.0$ & $1.8 \pm 1.2$ & NS \\
\hline Diabetes mellitus [\%] & 29 & 33 & NS \\
\hline $\begin{array}{l}\text { Hs-CRP [mg/l], } \\
\text { median (IQR) }\end{array}$ & 1.35 & 1.1 & NS \\
\hline
\end{tabular}

$P M I$ - procedural myocardial infarction 
Table IV. Angiographic and interventional characteristics of the study population

\begin{tabular}{|lccc|}
\hline Type of statin & $\begin{array}{c}\text { PMI } \\
(n=52)\end{array}$ & $\begin{array}{c}\text { Non-PMI } \\
(n=366)\end{array}$ & Pvalue \\
\hline Lesion located in LAD, LCX, RCA, SVG, LMCA [\%] & $44 / 37 / 23 / 0 / 2$ & $38 / 30 / 31 / 1 / 4$ & NS \\
\hline One/two/three-vessel disease [\%] & $40 / 21 / 37$ & $43 / 32 / 24$ & NS \\
\hline Lesions & & 5 & NS \\
\hline A [\%] & 6 & 28 & NS \\
\hline B1 [\%] & 21 & 33 & NS \\
\hline B2 [\%] & 25 & 28 & 0.03 \\
\hline C [\%] & 42 & $83 \pm 10$ & NS \\
\hline Stenosis of treated lesions [\%] & $86 \pm 10$ & 7 & NS \\
\hline Intracoronary thrombosis [\%] & 15 & $1.2 \pm 0.5$ & NS \\
\hline Treated lesions [mean] & $1.3 \pm 0.5$ & 83 & NS \\
\hline Stented patients [\%] & 88 & $1.1 \pm 0.2$ & NS \\
\hline Stents per patient [\%] & $1.2 \pm 0.2$ & $26 \pm 27$ & 0.02 \\
\hline Balloon inflation time [s] & $40 \pm 44$ & 100 & NS \\
\hline Angiographic success [\%] & 99 & 1 & NS \\
\hline Acute main or side branch occlusion [\%] & 6 & 1 & NS \\
\hline Reintervention within 24 $h$ [ $n$ ] & 0 & & \\
\hline
\end{tabular}

$P M I-$ procedural myocardial infarction

Table V. Predictors of peri-procedural myocardial infarction

\begin{tabular}{|lcc|}
\hline & Odds ratio (95\% Cl) & $P$ value \\
\hline Age & $1.03(0.98-1.08)$ & NS \\
\hline Gender & $1.98(0.76-5.13)$ & NS \\
\hline Hypertension & $0.87(0.37-2.08)$ & NS \\
\hline $\begin{array}{l}\text { History of myocardial } \\
\text { infarction }\end{array}$ & $1.57(0.71-3.46)$ & NS \\
\hline Total cholesterol & $0.87(0.39-1.95)$ & NS \\
\hline HDL cholesterol & $1.62(0.56-4.71)$ & NS \\
\hline LDL cholesterol & $1.15(0.52-2.55)$ & NS \\
\hline Triglyceride & $0.81(0.50-1.32)$ & NS \\
\hline Log hs-CRP & $1.38(1.06-1.81)$ & 0.02 \\
\hline Clopidogrel pre-treatment & $0.59(0.26-1.32)$ & NS \\
\hline Type C lesion & $1.12(0.43-2.90)$ & NS \\
\hline Balloon ischaemic time & $1.01(1.00-1.02)$ & 0.02 \\
\hline
\end{tabular}

resulting from reduction of adhesion molecule expression in ischaemic myocardium, and an increase in the bioavailability of nitric oxide in the coronary microvasculature $[4,7,8,10,11]$. Moreover, some investigations have demonstrated reduction of inflammatory markers within $24 \mathrm{~h}$ following a single dose of statin administration [15]. Although the role of pre-treatment with statins in patients undergoing $\mathrm{PCl}$ for stable angina pectoris is not clear, all the enrolled patients were pre-treated with statins at least for two days prior to $\mathrm{PCl}$.
Procedural myocardial infarction remains clinically silent in the vast majority of cases and its only manifestation is the subsequent release of biomarkers of myocardial injury. As demonstrated repeatedly, the incidence of PMI is substantially dependent on the cut-off value of chosen biomarkers, marker assay, and frequency of blood analyses. In non-selective, multimarker series, the incidence of PMI ranged from $1 \%$ to $49 \%$ [11].

C-reactive protein has been widely considered to be a non-specific but sensitive marker of acute inflammatory response. Ridker et al. suggested that measurement of CRP may provide a useful method of assessing the risk of cardiovascular disease in apparently healthy persons, and even in patients prior to $\mathrm{PCl}$ [16]. However, it seems to be likely that CRP level is not related directly to the extent of coronary atherosclerosis but more substantially to vulnerability of atherosclerotic plaques $[17,18]$. Therefore, CRP by some undefined mechanism influences the outcome of $\mathrm{PCl}$, even in patients with stable coronary artery disease. Saadeddin et al. found pre-procedural CRP elevation in $41 \%$ of patients with stable angina undergoing $\mathrm{PCl}$, associated with 2.3-fold higher risk of developing PMI. However, because of the small size of the patient cohort enrolled in their study ( $n=85)$, the validity of their conclusion seems to be limited [14]. Interestingly, Park et al. demonstrated the association of pre-procedural CRP level higher than normal $(\geq 3 \mathrm{mg} / \mathrm{l})$ with the incidence of drug-eluting stent thrombosis during the 3.9-year 


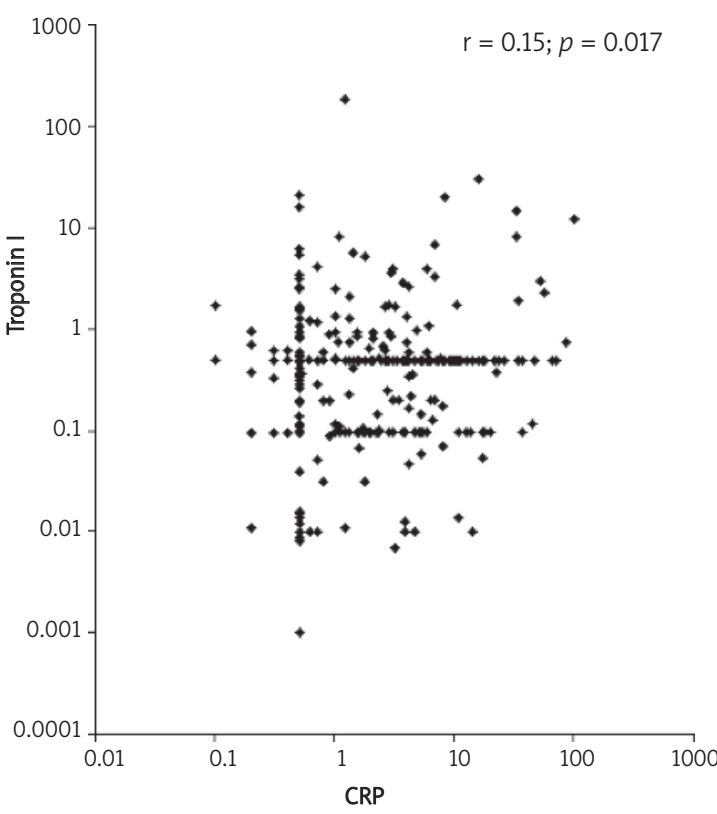

Figure 1. Correlation between troponin I and hs-CRP

follow-up of electively treated patients with stable angina [19]. Moreover, Briguori et al. showed that a single high loading dose of atorvastatin reduces the incidence of $\mathrm{PMI}$ in elective $\mathrm{PCl}$, especially in high CRP level patients [10]. On the other hand, a recent meta-analysis by Kinlay suggested that most of the anti-inflammatory effect of LDLlowering therapies is related to the magnitude of change in LDL cholesterol. Thus, the potential nonLDL ("pleiotropic") effects of statins on inflammation are much smaller in magnitude than thought before [20]. Nevertheless, with an improved understanding of the pathophysiology of atherothrombosis, advanced technology, and an increased ability to efficiently screen and reliably measure molecular, cellular, and other blood-borne biomarkers, the overall role of biomarkers including CRP in clinical decision making is expected to expand exponentially [21].

Although all the patients in our study were pretreated with statins for at least two days before $\mathrm{PCl}$, the level of pre-procedural CRP remains an important risk factor for elective $\mathrm{PCl}$. Therefore, based on these results it seems to be reasonable to include CRP in the clinical decision-making process and timing of $\mathrm{PCl}$ in patients with stable angina pectoris. We could hypothesize that in patients with a high CRP level the elective PCI might be postponed, and patients should be pre-treated aggressively with statins to reduce the CRP level as much as possible.

Balloon ischaemic time proved to be an independent procedural predictor of PMI in this study. However, this finding must be understood in the context of design of this retrospective study. Since a fair number of procedure-related risk factors

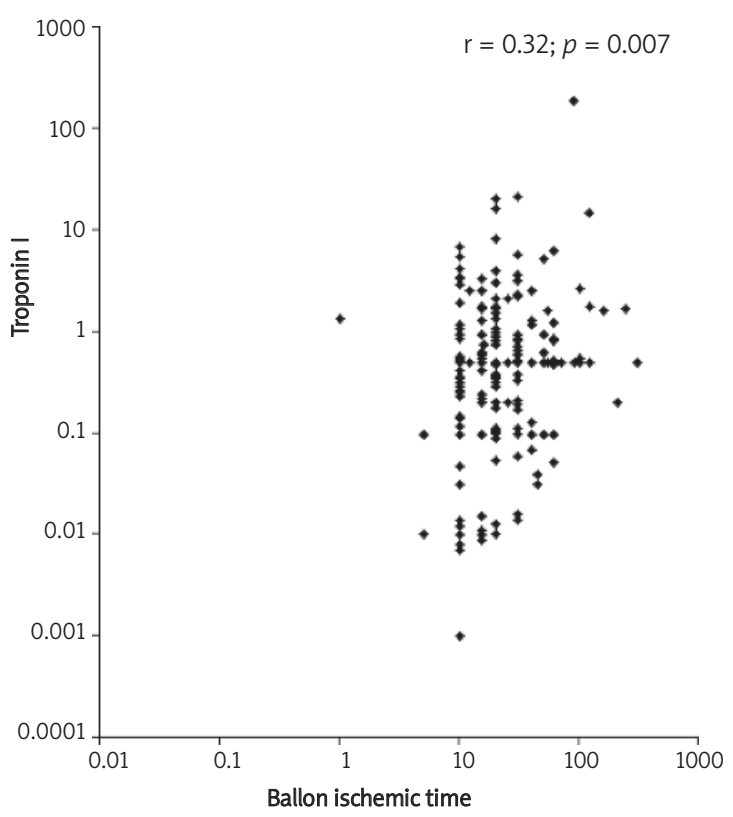

Figure 2. Correlation between troponin I and balloon ischaemic time

were not recorded, it seems likely that we might have missed the opportunity to identify additional procedural predictors of PMI. Thus, on the basis of existing data, balloon ischaemic time as an independent PMI predictor might represent not only longer duration of procedural myocardial ischaemia, but also more complex intervention that was caused by more complex initial coronary findings. Moreover, balloon inflation time was a statistically significant predictor of $\mathrm{PMI}$, but its odds ratio was only 1.01 (95\% Cl 1.001-1.020; $p=0.02)$. Therefore, based on these data its role in pathophysiology of PMI seems to be rather limited.

\section{Study limitations}

The present study has several limitations. First, the limited number of enrolled patients and low incidence of PMI resulted in a relatively small size of the PMI group (52 pts.). Therefore, a type II statistical error cannot be ruled out definitely and some additional factors might play a significant role in the pathophysiology of the PMI. Moreover, the analyses of subgroups have in this study only minimal relevance. Therefore, a statistically significant difference in the incidence of PMI in patients pre-treated with simvastatin $40 \mathrm{mg}$ cannot be considered a result of this study. Second, this study analysed retrospectively data collected prospectively. In this light it has to be understood that at the time of intervention not all parameters of possible interest were recorded. Thus, any generalizations based on our results should be made with caution. Third, blood samples for biomarkers were taken prior to the $\mathrm{PCl}$ and then within 16-24 hours thereafter. Therefore, this study 
design cannot rule out for certain any additional events that would be detected within 24-48 $\mathrm{h}$ after the $\mathrm{PCl}$. Fourth, data on the duration of statin pretreatment longer than two days are not available.

These results suggest that $\mathrm{C}$-reactive protein and balloon ischaemic time are independent predictors of $\mathrm{PMI}$ in stable angina patients on statin therapy. Future studies are required to determine whether the reduction of CRP level should be recommended prior to elective $\mathrm{PCl}$.

\section{Acknowledgments}

The work was supported by the grant of the Ministry of Health of the Czech Republic Nr. 00064203.

The authors thank Eva Hansvenclova for her assistance in the data collection and analysis.

\section{References}

1. Thygesen K, Alpert JS, White HD on behalf of the Joint ESC/ACCF/AHA/WHF Task Force for the Redefinition of Myocardial Infarction. Universal redefinition of myocardial infarction. Eur Heart J 2007; 28: 2525-38.

2. Cavallini C, Savonitto S, Violini R, et al.; Italian "Atherosclerosis, Thrombosis, and Vascular Biology" and "Society for Invasive Cardiology-GISE" Investigators. Impact of the elevation of biochemical markers of myocardial damage on long-term mortality after percutaneous coronary intervention: results of the CKMB and PCl study. Eur Heart J 2005; 26: 1494-8.

3. Prasad A, Singh M, Lerman A, Lennon RJ, Holmes DR, Rihal CS. Isolated elevation in troponin $T$ after percutaneous coronary intervention is associated with higher long-term mortality. J Am Coll Cardiol 2006; 48: 1765-70.

4. Vlachopoulos C, Aznaouridis K, Dagre A, et al. Protective effect of atorvastatin on acute systemic inflammationinduced endothelial dysfunction in hypercholesterolemic subjects. Eur Heart J 2007; 28: 2102-9.

5. Danesh RD, Kanwar YS. Modulatory effects of HMG-CoA reductase inhibitors in diabetic microangiopathy. FASEB J 2004; 18: 805-15.

6. Ridker PM, Danielson E, Fonseca FAH, et al. Rosuvastatin to prevent vascular events in men and women with elevated C-reactive protein. N Engl I Med 2008; 359: 2195 207.

7. Pasceri V, Patti G, Nusca A, Pristipino C, Richichi G, Di Sciascio G. Randomized trial of atorvastatin for reduction of myocardial damage during coronary intervention. Results from the ARMYDA (Atorvastatin for Reduction MYocardial Damage during Angioplasty) Study. Circulation 2004; 110: 674-8.

8. Veselka J, Procházková Š, Duchoňová R, Homolová I, Tesař D, Bybee KA. Preprocedural statin therapy reduces the risk and extent of cardiac biomarker release following percutaneous coronary intervention. Heart Vessels 2006; 21: $146-51$.

9. Veselka J, Zemánek D, Hájek P, et al. Effect of two-day atorvastatin pretreatment on the Incidence of periprocedural myocardial infarction following elective percutaneous coronary intervention: a single-centre, prospective, and randomized study. Am J Cardiol 2009; 104: 630-3.
10. Briguori C, Visconti G, Focaccio A, et al. Novel approaches for preventing or limiting events (Naples) II trial: impact of a single high loading dose of atorvastatin on periprocedural myocardial infarction. J Am Coll Cardiol 2009; 54: 2157-63.

11. Herrmann J. Peri-procedural myocardial injury; 2005 update. Eur Heart J 2005; 26: 2493-519.

12. Lanzer P, Prechelt L. Spelling out risk reduction strategies for intracoronary stenting. Eurolnterv 2008; 3: 622-6.

13. Sattler KJE, Herrmann J, Yun S, et al. High high-density lipoprotein-cholesterol reduces risk and extent of percutaneous coronary intervention-related myocardial infarction and improves long-term outcome in patients undergoing elective percutaneous coronary intervention. Eur Heart J 2009; 30: 1894-902.

14. Saadeddin SM, Habbab MA, Sobki SH, Ferns GH. Association of systemic inflammatory state with troponin I elevation after elective uncomplicated percutaneous coronary intervention. Am J Cardiol 2002; 89: 981-3.

15. Li JJ. Rapid effects of lipid profile and C-reactive protein by simvastatin in patients with hypercholesterolemia. Clin Cardiol 2003; 26: 472-6.

16. Ridker PM, Cushman M, Stampfer MJ, Tracy RP, Hennekens CH. Inflammation, aspirin, and the risk of cardiovascular disease in apparently healthy men. N Engl J Med 1997; 336: 973-9.

17. Veselka J, Procházková Š, Duchoňová R, et al. Relationship of $\mathrm{C}$-reactive protein to presence and severity of coronary atherosclerosis in patients with stable angina pectoris or a pathological exercise test. Coron Artery Dis 2002; 13: 151-4.

18. Dimitrijevic O, Stojčevski BD, Ighnjatovič S, Singh NM. Serial measurement of C-reactive protein after acute myocardial infarction in predicting one-year outcome. Int Heart J 2006; 47: 833-42.

19. Park DW, Yun SC, Lee JY, et al. C-reactive protein and the risk of stent thrombosis and cardiovascular events after drug-eluting stent implantation. Circulation 2009; 120: 1987-95.

20. Kinlay S. Low-density lipoprotein-dependent and -independent effects of cholesterol-lowering therapies on C-reactive protein: a meta-analysis. J Am Coll Cardiol 2007; 49: 2003-9.

21. Karra R, Becker RC. Biomarkers for outcomes following acute coronary syndromes. Arch Med Sci 2010; 6: S55-63. 